\title{
Comoé National Park - a refuge for critically endangered vulture species in West Africa.
}

\section{Volker Salewski}

Michael-Otto-Institut im NABU, Goosstroot 1, 24861 Bergenhusen, Germany Volker.Salewski@NABU.de

http://dx.doi.org/10.4314/vulnew.v71i1.4

\section{A preliminary report of a visit to the park, 28 Dec 2016 - 07 Feb 2017}

Comoé National Park (hereafter CNP) is, at about $11,500 \mathrm{~km}^{2}$, one of the largest national parks in West Africa. It is situated in north-eastern Côte d'Ivoire. Especially in the south-west, the park consists of a savannah-forest mosaic with gallery forest along the main rivers (Comoé, Iringou, Kongo) (Fig. 1).

CNP is known to host five species of vultures: Palm-nut Vulture Gypohierax angolensis (frequent), Hooded Vulture Necrosyrtes monachus (frequent), White-backed Vulture Gyps africanus (common), Lappet-faced Vulture Torgos tracheliotus (uncommon) and Whiteheaded Vulture Trigonoceps occipitalis (frequent) (Salewski 2000).

Between 1994 and 2000, the author spent in total about 24 months in CNP, mostly in the south-west, with regular visits to the north-west in
1998/99. The author revisited the south-west again for two visits of about two weeks each in January/February 2015 and 2016. During the recent visits it was apparent that large antelopes (roan antelope Hippotragus equinus, hartebeest Alcelaphus buselaphus) were apparently much more frequent in the south-west compared to the 1990 s and that the numbers of vultures (mainly White-backed Vultures, but also Palm-nut Vultures, Hooded Vultures and White-headed Vultures) seen were surprisingly high with a high proportion of immature birds indicating good breeding success in recent years. The observation of a relatively high density of vultures, with good breeding success, runs counter to the trend described for Africa in general and West Africa in particular 
(Thiollay 2006, Ogada et al. 2015) and let to the initiation of the Vulture Conservation Project of the Naturschutzbund Deutschland, BirdLife partner in Germany (NABU). The aims of a first trip to CNP in the framework of the project in 2016/17 were:

1. To search for vultures and vulture nests to assess the status of the different species in the southwest of the park;

2. To capture two Whiteheaded Vultures or White-backed Vultures to equip them with satellite tags;

3. To introduce the project to the park-authorities of the Office Ivorien des Parcs et Reserves (OIPR), to the Deutsche Gesellschaft fuer Internationale Zusammenarbeit (GIZ), to the authorities of the Ecological Research Station of the University of Würzburg, Germany, and to professors of the University of Abidjan, all four institutions cooperating together in the park.

Here, the first results are presented in a nutshell.

\section{Search for vultures}

Between 29 December 2016 and 7 February 2017 search trips were performed on 28 days during which about $475 \mathrm{~km}$ were walked according to the GPS (Fig. 1).

During these trips (Fig. 2) individuals of three species of vultures (excluding Palm-nut Vulture) and 23 species of other raptors (including Palm-nut Vulture) were encountered (Fig. 3). Fig. 3 does not include vultures that were attracted during the attempt to catch them or the hundreds of Yellowbilled Kites and Black Kites being attracted by bush-fires. There was a clear pattern in the distribution of vultures. Although raptors in general were encountered more or less frequently on all trips, vultures were only seen in the northern parts of the research area, with the exception of one White-headed Vulture. Furthermore, White-headed Vultures were in general seen further south compared to White-backed Vultures. A Hooded Vulture was seen only once in the vicinity of a nest. 


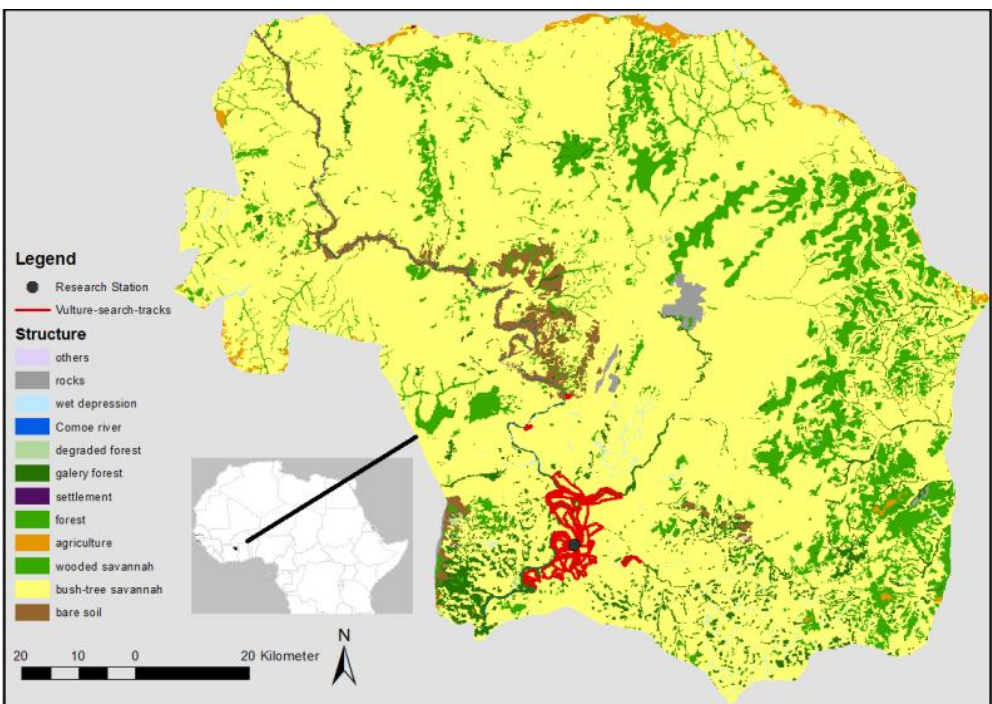

Figure 1: Comoé National Park. The Ecological Research Station and tracks walked in search for vultures are shown in the south-west of the park.

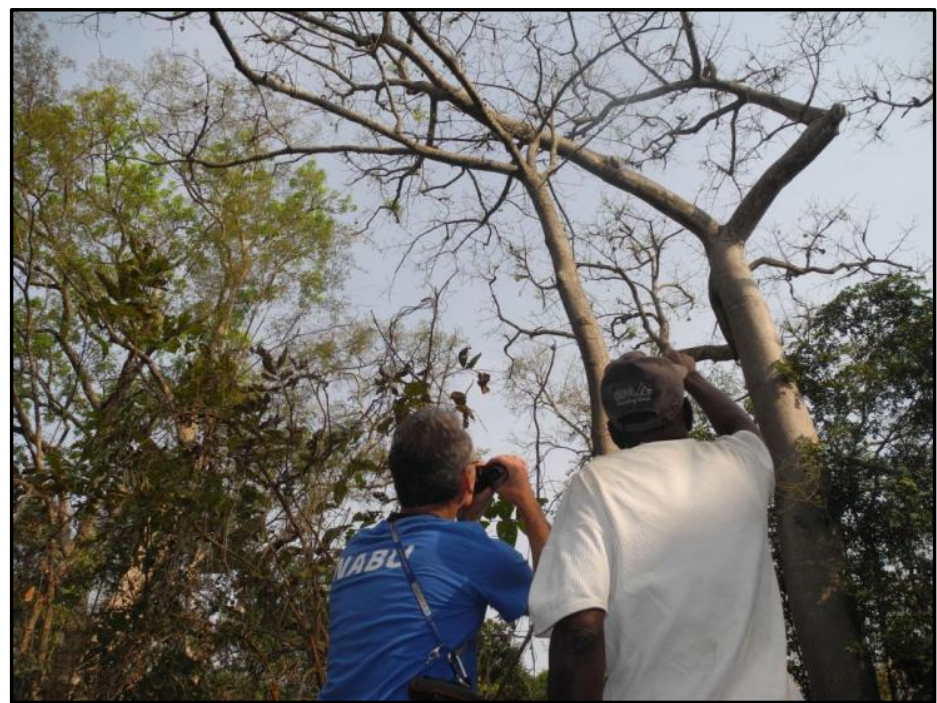

Figure 2: The author and K. Kouadio inspect Kapok trees for vulture nests. 
In total twelve nests of White-backed Vultures, two nests of White-headed Vultures and one nest of a Hooded Vulture were discovered (Fig. 4). All nests were in Kapok trees Ceiba pentandra (Fig. 5). All nests of White-backed Vultures as well as the nest of the Hooded Vulture were in the gallery forest, whereas the two nests of White-headed Vultures were in isolated forests (Fig. 4). The nests of White-backed Vultures seemed to be clustered in some areas with one case of two nests in a single tree.

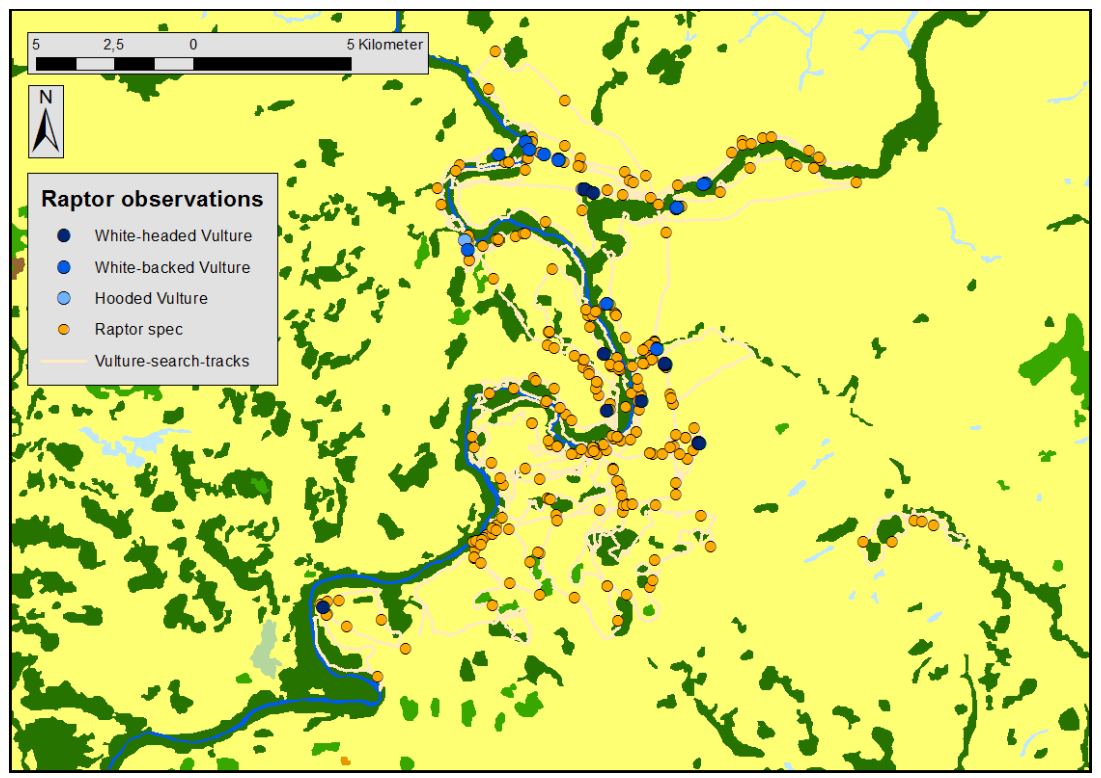

Figure 3: Vultures and other raptors (including Palm-nut Vulture) encountered in the south-west of CNP. The two northernmost search-tracks (see Fig. 1) are not shown. Note that all areas depicted in green are forests despite that some are assigned to "Wooded Savannah" in Figure 1. 


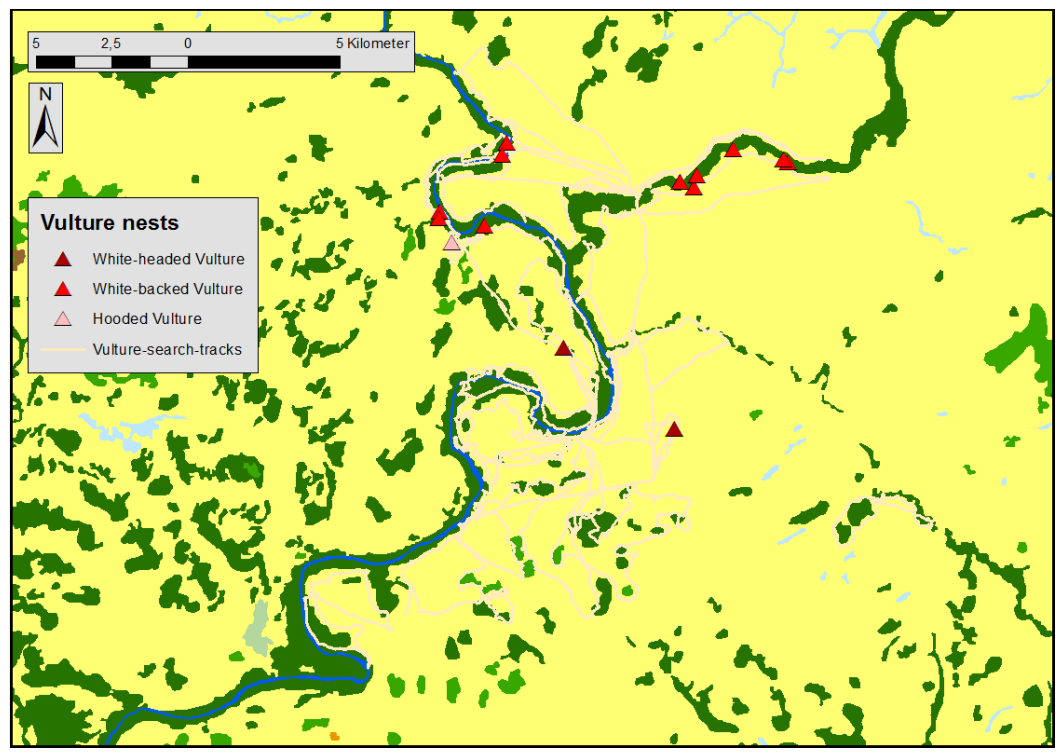

Figure 4: Vulture nests in Comoé National Park in January 2017. For Whitebacked Vulture one of the symbols indicates two nests that were situated in a single tree. Northernmost search-tracks are not shown. All areas in green are forests despite that some are assigned to "Wooded Savannah" in Fig. 1. Some smaller forests are not shown.

\section{Capture attempts}

On four days attempts were made to catch vultures with snares and a goat as bait. On the first day a Whitebacked Vulture was captured, but escaped again, probably because only a toe was caught in the snare. After this failure no vultures approached the bait for the rest of the day and the next day. A second capture attempt on two consecutive days one week later attracted approximately forty vultures (Fig. 6).
The first birds at the bait were Bateleurs Terathopius ecaudatus, but no vultures approached the bait on the ground. Shortly before terminating the last capture attempt the following vultures were seen on a tree near the bait or on the ground: White-backed Vulture: 6 adults, 23 immatures, White-headed Vulture: 1 adult, 5 immatures, Hooded Vulture: 1 immature. A few more vultures were sitting on more distant trees. 

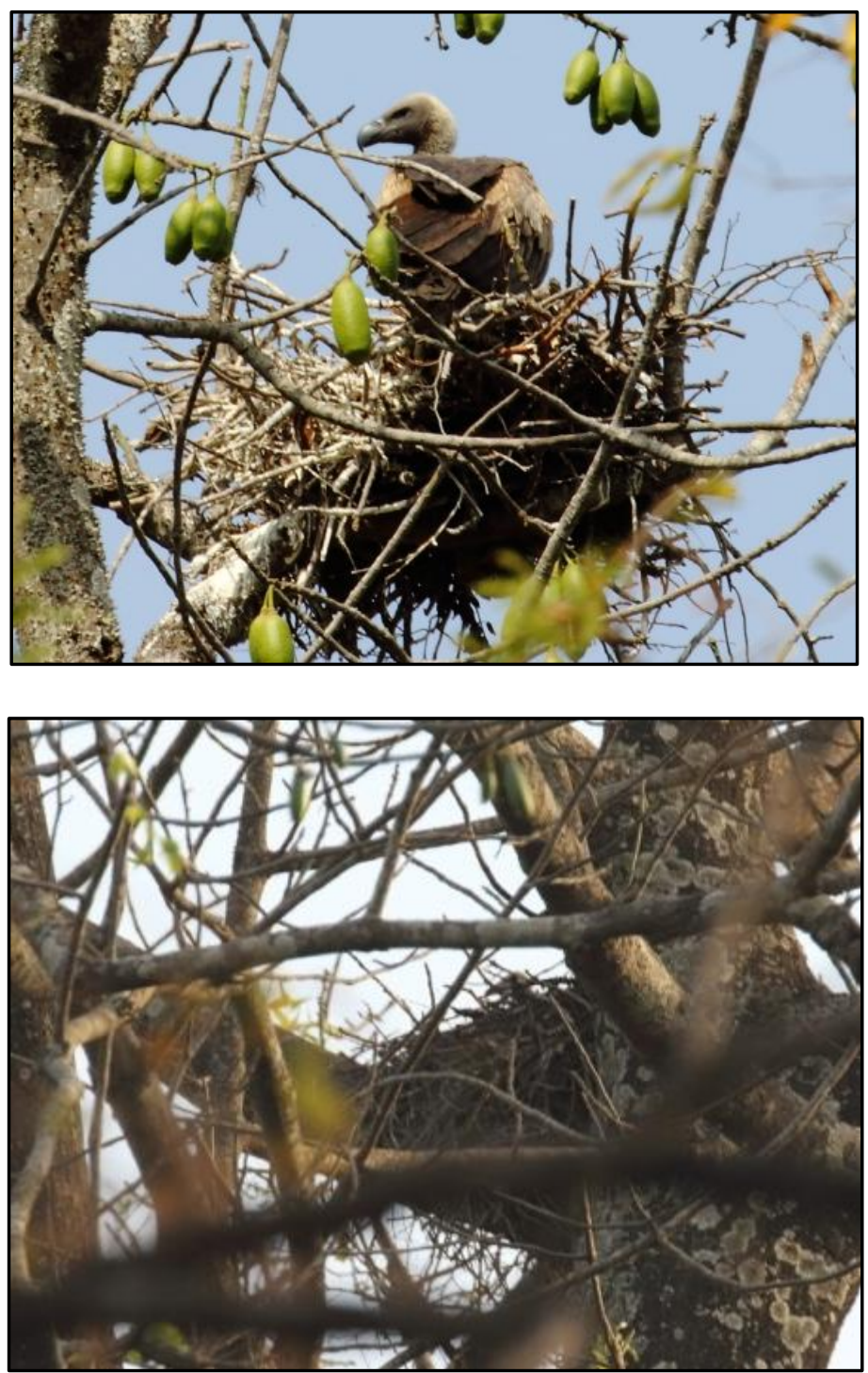

Figure 5: Breeding Vultures in Comoé National Park in January 2017. Whitebacked Vulture (top), Hooded Vulture (bottom) 


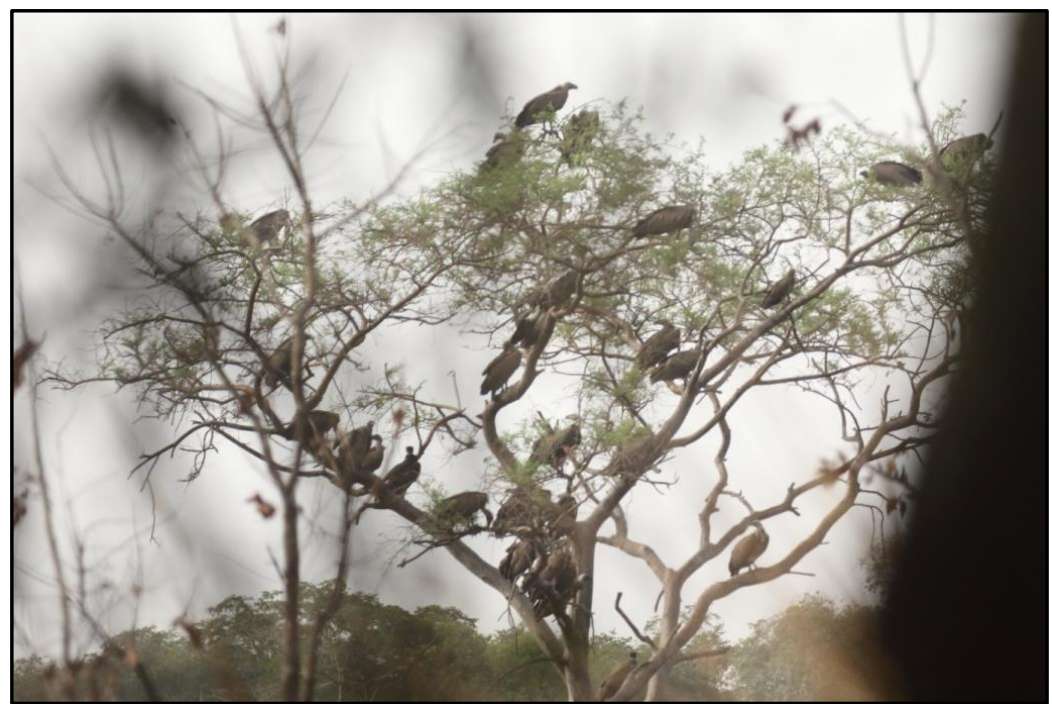

Figure 6: Vultures attracted by a carcass beneath the tree on which they perch

\section{Project partners}

During the official inauguration of the Ecological Research Station in the park the project was introduced to the OIPR director of the park M. Roger Yao Kouadio, several representatives of the University of Würzburg, Germany, and to Dr. N'Golo A. Kone, the Ivorian representative of the Ecological Research Station (Fig. 7). All of them, including Prof. K.E. Linsenmair, the German director of the Ecological Research Station, expressed their motivation to support the project because vultures are an indicator of functioning savannah ecosystems and could therefore serve as an "umbrella species" to promote the awareness of the importance for conservation of soudanian-guinean savannah-biomes in the park itself.

At the University of Nangui Abrogouain in Abidjan, the possibilities of two master-theses in the framework of the project were discussed with Dr. N'Golo A. Kone and Prof. Souleymane Konate. The first thesis is aimed to investigate the distribution of vultures in CNP, and the second, in co-operation with an anthropologist, is planned to investigate the role of vultures in the Ivorian society and the reasons for the decline of vulture populations in 
the country. Furthermore, in a responsible for the activities of the meeting at the GIZ office the project GIZ in CNP expressed his support was discussed and U. Caspary who is for the project.

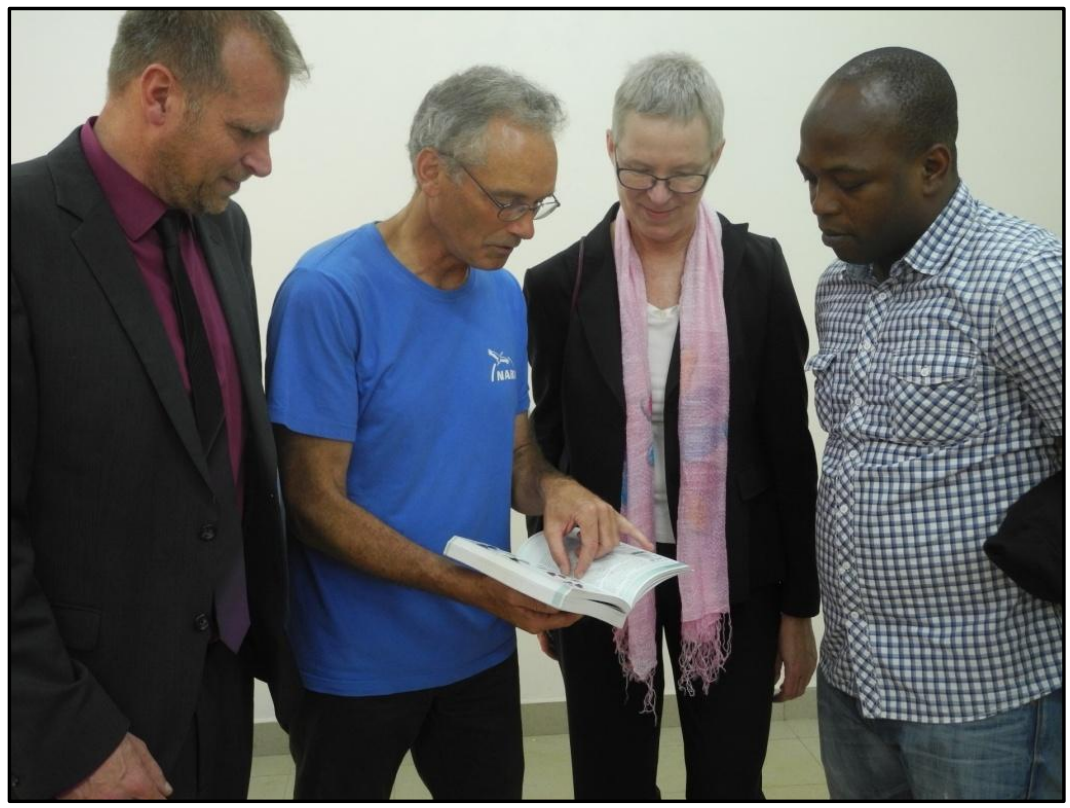

Figure 7: The author explains the vulture project to representatives of the Universities of Würzburg, Germany and Abidjan, Côte d'Ivoire. From left: Prof. Thomas Schmidt, University of Würzburg, German director of the Ecological Research Station; Dr. Volker Salewski, NABU; Prof. Barbara Sponholz, vice-president of the University of Würzburg; Dr. N'Golo A. Kone, University of Nangui Abrogoua, Abidjan, Ivorian representative of the Ecological Research Station.

\section{Perspective}

Vultures of three species (excluding Palm-nut Vulture) were observed and a total of 15 nests found in CNP between December 2016 and February 2017. The conservation status of these species is "critically endangered" (IUCN 2016) and in West Africa they occur almost exclusively in large reserves (Thiollay 2006). As most of the 
dangers that are listed by Ogada et al. (2015) are not encountered in CNP, the park may serve as "vulturesave-zone" and may serve as a key area for the conservation of vultures in West Africa. There are, however, indications that vultures reduced their range and that they were more abundant in more southern areas in CNP about 20 years ago (V. Salewski, pers. obs.). The reason for this potential reduction will be investigated in the future.

Besides the two projects in cooperation with the University of Nangui Abrogoua in Abidjan attempts to capture vultures to employ satellite tags will be intensified to investigate home ranges of different age classes of the respective species. It was shown that it is possible to bait a good number of vultures and intensified attempts to capture vultures should be successful in the future.

All coordinates of raptors seen less than $500 \mathrm{~m}$ away from the author are deposited in the African Raptor DataBank (http://www.habitatinfo.com/ardb_re sources/). The is a project of the NABU International Naturschutzstiftung.

\section{References}

IUCN (2016) The IUCN Red List of Threatened Species. Version 2016-2. <www.iucnredlist.org>. Downloaded on 22 February 2017.

Ogada, D. et al. 2015. Another continental vulture crisis: Africa's vultures collapsing toward extinction. Conservation Letters 9: 89-97.

Salewski, V. 2000.The birds of Comoé National Park, Ivory Coast. Malimbus 22: $55-76$.

Thiollay, J.-M. 2006. The decline of raptors in West Africa: long-term assessment and the role of protected areas. Ibis 148: 240-254 